\title{
The Cost of Going Green in the Wine Industry
}

Keywords: Wine cleaning; Green chemicals; Salinity reduction Sustainable wine production

\begin{abstract}
Salinity build up in the San Joaquin Valley has been identified as one of the most important issues affecting water quality in California. As the wine industry continues to grow, it becomes even more imperative to find new ways to reduce salinity buildup. The cleaning process is one aspect of production where there is potential to reduce the overall environmental impact. This study compares various new wine tank cleaning methods and "green" chemicals based on their cleaning capabilities, salinity content, and utilization costs. Viable, cost effective solutions are found that have the potential to drastically reduce salinity in waste streams while reducing utilization costs as well. Specifically, the conversion of the standard Sterox K cleaning chemical to the newly developed Vitipure across all California wine, could reduce total loads of sodium ( $\mathrm{Na}$ ) and potassium $(\mathrm{K})$ in winery water waste streams to negligible amounts while decreasing utilization costs by at a minimum of \$1.1 IUSD per 100,000 litre tank. The reduction in $\mathrm{Na}$ and $K$ has the potential to drastically affect effluent waste streams across California as well as globally.
\end{abstract}

\section{Introduction}

Cleaning and disinfecting surfaces for food contact is essential to the palatability and safety of food for human consumption. The United States is a world leader in regards to food safety, in large part due to programs like Hazard Analysis of Critical Control Points (HACCP), good manufacturing practices (GMP's), and a focus on effective cleaning and sanitizing. One of the consequences of the need for chemical cleaners in the food industry is the production of environmentally harmful wastes. Of particular concern for food and wine processors are the saline effluents produced in the cleaning phase, after initial rinsing, and prior to secondary rinsing and sanitizing. The detergents come in a variety of formulations with builders, water treatment chemicals, emulsifiers, and surfactants. Effluent electrical conductivity (EC), due to the saline nature of many of these detergents, has effects on the ground water and soil quality of the environments they are eventually discharged into, potentially causing damage to plant and wildlife in the area and causing severe economic repercussions. It is in the interest of human, plant, and animal populations in arid regions like the Central Valley of California and elsewhere around the world, to develop technologies that reduce or eliminate the impact that food and wine processor's saline effluents have on the environment.

Salinity and mineral build up in the San Joaquin Valley, specifically sodium $(\mathrm{Na})$ and potassium $(\mathrm{K})$, has been identified as a major issue affecting water quality in California. Soil salinity poses a threat to several industries including municipal water and wastewater treatment plants, water purveyors, irrigated agriculture, confined animal operations, agri-business, and food processing, among others. As the food processing and wine industries in the San Joaquin Valley continue to grow, their impact on the local environment also grows. Reducing salinity buildup in the Central Valley is necessary
Journal of

Food Processing \& Beverages

\author{
Michael McCullough ${ }^{1 *}$, Kyle Manchester ${ }^{2}$ and \\ GourChoudhury \\ ${ }^{1}$ Agribusiness Department, California Polytechnic State University, \\ San Luis Obispo, USA \\ ${ }^{2}$ Food Science and Nutrition Department, California Polytechnic \\ State University, San Luis Obispo, USA \\ ${ }^{3}$ Food Science and Nutrition Department, California Polytechnic \\ State University, San Luis Obispo, USA
}

\section{*Address for Correspondence}

Michael McCullough, Agribusiness Department, California Polytechnic State University, San Luis Obispo, USA, Tel: 805-756-509; E-mail: mpmccull@calpoly.edu

Submission: 07 January, 2016

Accepted: 23 February, 2016

Published: 29 February, 2016

Copyright: ๑ 2016 McCullough M, et al. This is an open access article distributed under the Creative Commons Attribution License, which permits unrestricted use, distribution, and reproduction in any medium, provided the original work is properly cited.

Reviewed and approved by: Dr. Andrew Reynolds, Department of Viticulture, Brock University, Canad

to maintain the quality of water enjoyed by local residents, and allow for the continued expansion of food processing and wine industries in the area.

Cleaning and sanitation chemicals are a major source of salts that, if controlled, would assist in reducing salinity build-up throughout the state. In winemaking and other food processing operations, these practices are also among the largest uses of water and are typically some of the largest sources of salts in process wastewater. Indeed, they can contribute to as much as $30 \%$ of processing energy use for a facility.

If salinity continues to increase at the projected rate, the increase in direct annual costs to San Joaquin Valley businesses will be between $\$ 1$ billion and $\$ 1.5$ billion by 2030 [1]. Increasing the cost of regulation to food producers as little as $1 \%$ is estimated to drive between 0.5 and $20 \%$ of production out of the region [2,3]. Developing methods of cleaning that are aimed at lowering effluent salinity would be extremely beneficial to manufacturers as well as the communities in which they operate.

All too often when problems such as this arise in production agriculture there is a strong push to pass regulatory policy without an understanding of potential unforeseen costs. When this happens, the policy, which was designed with good intentions, can potentially become ineffective and far more costly to society then dealing with the problem post facto. The goal of this research was to explore potential methods wineries could voluntarily employ to reduce salinity in their effluent streams. Various methods were tested and their cleaning capabilities, salinity content, and utilization costs were recorded. The outcomes of the study have produced economically and environmentally viable alternative solutions to current cleaning practices in the wine industry. If widely adopted, these solutions not 
only have the potential to reduce harmful waste streams but eliminate the necessity of potential government regulation. In the sections that follow a brief literature review presents research associated with the potential impact of salinity in waste streams. The solutions tested are described and their outcomes are presented with recommendations.

\section{Literature Review}

GMP's and HACCP are standard practices within most facilities to ensure the safety and quality of food produced in their factories. They include comprehensive evaluation of cleaning regimens, foot traffic through the factory, hand cleaning requirements, sanitation verification, and many other food safety related practices aimed at preventative control and corrective actions [4].

A typical industrial cleaning regimen includes an initial rinse step for gross soils removal, one or more chemical cleaning steps to remove any residual soils, a second rinsing step to remove potentially harmful chemical residues, and a final sanitizing step to kill any remaining microorganisms [5]. The cleaning phase results in the largest reduction in microbial load on surfaces and can be considered the most important step in a cleaning and sanitizing regimen. Microbial loads as great as $10^{3}$ cells $\mathrm{cm}^{-2}$ are removed during cleaning, however some studies find reductions as low as 10 cells $\mathrm{cm}^{-2}$, possibly due to the soiling matrix in which the microorganisms reside [6].

Cleaning in the food industry can be detrimental to the environment due to the high electrical conductivity (EC) of most cleaning effluents, resulting from highly saline cleaners. Roughly an average of 1.2 milliSiemens per centimeter $(\mathrm{mS} / \mathrm{cm})$ or higher can be expected from typical winery effluents, however this number is highly variable [7]. High levels of salinity can lead to issues for vineyards, such as weight per berry reduction. In a 5-year study of salinity effects on irrigated field-grown grapevines, Sultana yields grown in $3.50 \mathrm{mS} /$ $\mathrm{cm}$ conductivity soil resulted in one year old pruning wood reductions of up to $54 \%$, berry weight reduction of $17 \%$, and yield per vine reductions of $30 \%$ [8]. Long-term saline irrigation has been shown to decrease chloride exclusion in Shiraz and chardonnay varieties of grape vines leading to salt toxicity, effecting plant metabolism and growth [9]. Elevated sodium in soil leads to lowered osmotic potential, structural degradation of soil, leaf burn, necrosis, and defoliation in woody species of plants, such as grape vines $[10,11]$. The level of salinity that produces negative effects on plant growth varies, but is dependent on soil texture, soil profile salt distribution, salt composition, plant stage of growth, and plant species. Generally, Plants begin to experience negative effects in soils exceeding $0.1 \%$ salt $(\sim 1.6 \mathrm{dS} / \mathrm{m})$, with sensitive plants, such as strawberries, carrots, and beans, having reduced yields with irrigation water conductivities as low as $0.7 \mathrm{mS} / \mathrm{cm} \mathrm{[12].}$

The effluent of most food and wine processing facilities is far higher in salinity than the receiving waters they are discharged into, and drainage to the ocean from California's Central Valley is inadequate to handle the large volume of saline discharge. Wineries in the central valley produced 4,950, 3,990 and 4,080 metric tons of fixed dissolved solids in 2003, 2004, and 2005 respectively, which correlate to $9 \%, 7 \%$ and $7 \%$ of the food and wine industries contributions to salt discharges in each of those years. Wineries use approximately
4,300 litres of water per ton of wine grapes processed. This is a low ratio compared to the approximate water use per ton of some other industries such as cherries, olives, and pears; 45,000, 30,300,15,800 litre/ton respectively [13].

Currently, the shortage of water in California is of the utmost concern, and use is poorly understood by many in the wine industry. Furthermore, water usage falls short of best practices in many cases. Water volume usage is underestimated in many wineries by as much as $80 \%$, with several wineries using as much as $8 \mathrm{~L}$ of water per bottle of wine produced, with $70 \%$ of that water eventually ending in waste streams; best practices report usages of as little as $0.4 \mathrm{~L}$ per bottle [14]. Closer monitoring and more carful managing of water use could produce improvements in many cases.

Saline-sodic soil conditions can be improved through $\mathrm{Ca}^{2+}$ cation exchange for $\mathrm{Na}^{+}$, which can be removed by percolating water. This requires a number of conditions to be effective, for example adequate water table depth and soil porosity for water movement, available water for over irrigation, exchangeable $\mathrm{Ca}^{2+}$, and a fairly level soil area to allow for homogeneous water distribution [15]. These are not practical solutions to the problem of saline-sodic soils on a large scale. The annual salt load from the Sacramento River, Yolo Bypass, and San Joaquin River is as much as 2.7 million tons annually, and agricultural land that is considered saline-sodic in the California Central Valley was 162,000 hectare in 2006 , or roughly $48 \%$ of the irrigated land in the survey, and up from just 33\% in 1985 [16]. Addressing the saline-sodic soils in the central valley and in arid regions globally will require an encompassing approach that intervenes prior to and after generation of saline effluents.

Solely reducing the amount of cleaning to reduce salinity in effluent streams is not a viable option. Poorly cleaned surfaces can lead to millions of dollars of product lost to the presence of pathogenic and spoilage microbes [17-19]. Therefore the problem exists in finding viable alternatives to current practices while maintaining industry standards in cleaning and sanitation. Developing effective methods of cleaning that are aimed at lowering effluent salinity would be beneficial to the farmer, food processor, and the communities in which they operate.

Options for treatment of saline wastewaters include ion exchange and reverse osmosis (RO), however these options produce their own concentrated wastes, usually need pretreatment, and require expensive specialized equipment $[7,16]$. Evaporation with thermal vapor recompression and RO has shown economic promise and is able to generate high quality water from waste streams; however the high initial capital investment for equipment puts this practice out of reach for many smaller facilities [20]. Regeneration of acidic and caustic cleaning solutions in a dairy facility with $\mathrm{RO}$ and nanofiltration has also been studied, and succeeded in reducing $76-90 \%$ of chemical oxygen demand (COD) in the cleaning waste, and concentrating the used caustic to $0.5-0.7 \%$, but they estimate concentrations of $1-2 \%$ are necessary to make the process economically viable [21]. Organic loading of winery waste can be addressed biologically with treatment ponds and bioreactors, however difficulties arise with effluent composition and volume changes throughout the year and not all constituents of the effluents are completely removed, such as certain 
phenolic compounds common in winery waste [22].

Treatment methods for food and wine processors waste streams will be critical to reducing the wastes impact on the environment. While improvements can be made to the quality of the effluents by optimizing cleaning and sanitizing procedures, treatment will always be necessary prior to disposal to remove the organic, inorganic, and microbial materials removed during cleaning. Recovery of clean water and other valuable constituents from waste streams may improve the economic outlook for more advanced treatment options, however the current financial reality of small to medium sized facilities prevents wide spread adoption.

\section{Methods}

Given the potential impact that a reduction in salinity would have on effluent streams, especially in the San Joaquin Valley, it was surprising to find very few, if any, alternative solutions. Various possible solutions were tested over the course of this research including, a high-pressure permanent water knife and 'green' chemicals. These alternative solutions were then compared with the standard methods for wine tank cleaning in order to determine their physical and economic effectiveness.

The first step in the development of new cleaning approaches was to adapt/develop an objective method to determine clean surfaces. Detecting soils residues on food processing surfaces is necessary in evaluating any cleaning and sanitation program, and there are a variety of ways to accomplish this. Cleanliness detection can be broadly categorized into direct methods and indirect methods. Direct methods refer to any measurement technique that relies on the soil itself as the signal for the method, while indirect methods rely on physical properties or some other effect related to cleanliness which can be used to derive the cleanliness of the surface. Indirect methods are often the quickest and most cost effective way to determine the cleanliness of a surface; however these methods can be prone to inconsistencies due to operator interpretation variance, matrix effects, or poor sensitivity. Indirect measurements are often employed in industrial settings due to their speed and cost effectiveness, however it's critical that likely soil type, possible interferences, and detection limits be considered in relation to risks associated with the surface and the appropriateness of the method.

A common indirect method in the food industry for cleaning validation is adenosine triphosphate (ATP) swabbing, where ATP, the energy currency synthesized in living cells, is used to produce a bioluminescent reaction, which can be measured to reflect the sanitary condition of the surface [23]. Sanitary is distinct from clean, where the former refers to the lack of microbial contamination on a surface, and the later refers to the absence of foreign material, microbial or not. While non-microbial organic material generally is not a threat to consumer health, it may harbor microbes, reduce the effectiveness of sanitizing agents, and provide nutrients for cell growth [24].

In the pharmaceutical industry it has become common, along with other analytical techniques such as HPLC, and UV/Vis spectroscopy, to use total organic carbon (TOC) analysis to validate the cleanliness of drug manufacturing equipment. TOC analysis, however, has an advantage over UV/Vis and HPLC because it is a non-specific method capable of detecting any material containing organic carbon. Using
HPLC, or UV-Vis would require specific methods for each substance to be detected, and therefore would not be appropriate for detecting complex soils of varying composition. TOC analysis detects any type organic carbon by oxidizing it to produce carbon dioxide, which can be quantified and used as a measure of cleanliness. Previous works report standard deviations in the method as low as 10.5 parts per billion (ppb) method detection limits as low as $50 \mathrm{ppb}$ and recoveries of between 80.0 and $95.9 \%$ of test residues from stainless steel $[25,26]$. TOC analysis, therefore, was adopted as the final method to determine cleaning efficiency.

TOC uses a polyester swab soaked in $1 \mathrm{~N}$ sodium hydroxide $(\mathrm{NaOH})$ to test a surface for residual carbon left after cleaning. An area of $5 \mathrm{~cm} \times 5 \mathrm{~cm}$ is thoroughly swabbed using a thermally attached polyester swab head soaked in $1 \mathrm{~N} \mathrm{NaOH}$. The swab head is then removed from the handle and dropped into a small flask where it is soaked in $1.0 \mathrm{~mL}$ of $\mathrm{NaOH}$ and $3.0 \mathrm{~mL}$ of nanopure water for one hour with stirring. After one hour the solution is neutralized with 1.0 $\mathrm{mL} 2 \mathrm{~N} \mathrm{HCl}$ prior to injection into the TOC analyzer, which works by combusting all of the present carbon to $\mathrm{CO}_{2}$. The $\mathrm{CO}_{2}$ gas is then delivered by an inert carrier gas to a membrane conductivity detector. The signal is compared to standards made of potassium biphthalate in nanopure water in the range of 0 to 100 parts per million organic carbons.

A tank-cleaning device was built to test the ability of high-pressure water spray to clean the inside of a soiled wine tank. The tank cleaner consisted of an X-shaped support that rested on the top edge of the tank, a pulley system that lowered and raised the cleaning portion of the device inside the tank, a three way spring loaded support to center the cleaning nozzles in the tank, and a rotating spray nozzle assembly. Various nozzle angles, pressures, and speeds were tested. After cleaning, 3 swab samples were collected from each third of the tank, making 9 samples collected from each cleaning at each pressure. A 9-sample replicate was also collected for each pressure, making 18 total samples at each pressure.

Nine liquid chemical alternatives were developed by Madison Chemicals Industries, Inc. Milton, Ontario Canada in partnership with the research team (Green Cleaner MPD, Aqua 9,000, PBC, Liquid HS, Liquid Clean Ox-Low Na, Liquid Clean Ox NF-Non Foaming, Liquid Clean-Ox Extra, Acid Clean-Ox V1, Acid Clean-Ox V2 now called Vitipure).The focus below is on the best performing chemical alternatives Liquid Clean-Ox and Vitipure. The chemical cleaning trials took place at a partnering wine producing facility in the San Joaquin Valley. Large commercial soiled wine tanks were rinsed at the recommended solutions for 45 minutes to achieve the minimum level of cleanliness of less than $0.0015 \%$ organic carbon per swabbed area. Estimates of effluent levels reported are averages over multiple cleans and statistical differences in means are calculated using the standard Tukey-Kramer mean comparison with a significance level of alpha $=0.05$. All estimated economic costs refer to manufacturer's specifications and suggested retail pricing.

The new cleaning methods are compared to a control using a $2 \%$ solution of Sterox $\mathrm{K}$, which is a commonly used cleaner at large scale wine processing facilities. Volumes of roughly $100 \mathrm{~L}$ of cleaner were circulated at 20 PSI for 30 minutes. Manufacturer recommendations require at least 15 minutes of circulation at $0.5-2 \%$ cleaner, with 


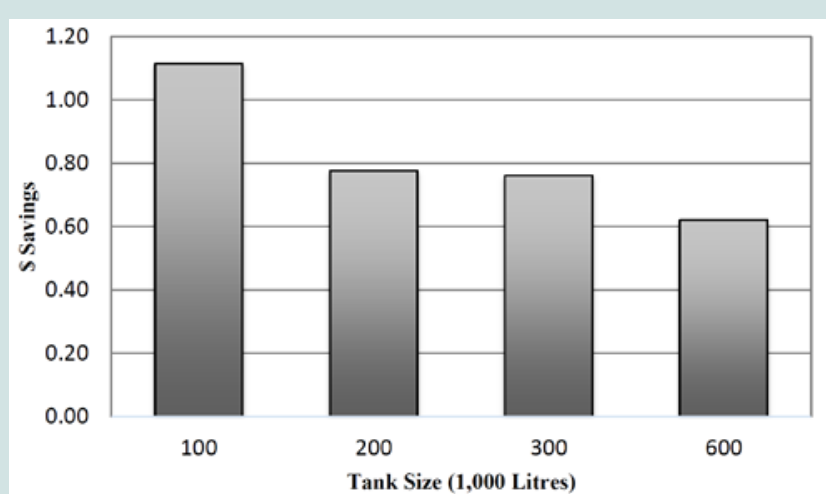

Figure 1: The change in cost savings per 100,000 litres when switching from Sterox $\mathrm{K}$ to Vitipure by tank size.

no suggestions for cleaning pressure or maximum cleaning time (http://www.sterokem.com/, Technical Data Sheet) manufactured by Sterokem LTD, Haifa, Israel.

\section{Results}

The high-pressure water knife cleaning system developed showed promise for reducing costs, water usage, and a source of contaminate waste stream. Spray angles of $30^{\circ}$ and $45^{\circ}$ were statistically better at cleaning than at a $60^{\circ}$ angle for nozzle heights of $1.0^{\prime \prime}$ and 1.5". At a spraying distance of $0.5^{\prime \prime}$, all three spray angles showed no difference in cleaning ability. The three nozzle heights were statistically the same in cleaning ability at angles of $30^{\circ}$ and $45^{\circ}$. No differences were observed for cleanliness between water knife spray times, however a slight trend was observed with averages of $0.0019,0.0017,0.0015$, and $0.0015 \%$ organic carbon for 2, 4, 6 and 8 seconds, respectively. Even at the fastest spray time of 2 seconds the detectable level of organic carbon was lower than the tested chemical methods of cleaning ( $\sim 0.004 \%$ organic carbon at the manufactures' specifications).

Nearly half the cost for the water knife is comprised of labour (Table 1), which upon installation and routine maintenance should be lower. Unfortunately, initial test of the water knife required a substantial increase in the required water usage per clean, over 4 times that of conventional and green chemicals (Table 1). However, the water knife is in the process of being designed to use recycled water so that the total amount of water necessary to clean a wine tank should be substantially lower. The prototype tested is expected to be modified depending on commercial tank specifications, so the per unit fixed cost has not been included in this analysis.

Table 1 illustrates cost comparisons of cleaning a 100,000 litre tank using the different developed methods and Sterox K. The current standard for cleaning soiled wine tanks is Sterox K priced at \$1.39 per pound. At the manufacturer's recommended usage of $1.5 \%$ by weight a single cleaning is estimated to be $\$ 25.12$. This estimate includes the cost of disposing sediment water at $\$ .92$ per thousand litres, labour, sanitizer, and fresh water at $\$ 0.15$ per thousand litres, costs that do not vary depending on cleaning chemical.

The green chemical alternatives developed substantially reduce the amount of $\mathrm{K}$ and $\mathrm{Na}$ in the waste stream and do so at a reduction in retail cost. The cost estimate for Liquid Clean Ox NF ( $\$ 2.59 /$ litre recommended at a $2 \%$ per volume solution) includes the standard rate of disposal for sediment water and yields a net savings of $\$ 1.20$ over the standard Sterox K. The estimate for Vitipure ( $\$ 4.68 /$ litre recommended at a $1 \%$ per volume solution) does not include the disposal cost, as there are no measureable quantities of $\mathrm{K}$ and $\mathrm{Na}$ in the waste stream. Furthermore, there appears to be diseconomies of scale in reducing cleaning costs per 100,000 litres. Figure 1 illustrates the decreased savings from $\$ 1.12$ per 100,000 litre using a 100,000 litre tank to $\$ 0.62$ per 100,000 litre using a 600,000 litre tank. Given that most wineries are using tanks substantially smaller than the large 600,000 litre tank, estimates of overall reduced costs will inevitably be conservative.

Findings of reductions of potential hazards in effluent are not insubstantial. Not only is the switch to green chemicals an environmental gain but they are currently more cost effective. Taking a simple back-of-the-envelope calculation to estimate the conservative costs of conversion to green chemicals, consider all wine produced in California. If the estimated 2,759,337,154 litres of California wine produced in 2013, Wine Institute estimates based upon revised TTB data Feb 11, 2015, was produced in the technically efficient 600,000 litre tanks, a conservative total of 4,600 tanks would be required for fermentation. At current production practices using Sterox K as the preferred cleaning chemical, a total of 2.06 ton of $\mathrm{K}$ and 9.60 ton of $\mathrm{Na}$ would need to be disposed of at a total cost of $\$ 279,013$ (Table 2). If all tank cleaning were to be converted to Vitipure then a savings of over $\$ 17,000$ state wide would be realized, this is a conservative estimate as most wine is produced in tanks much smaller than 600,000 litres, in addition to the almost complete reduction of $\mathrm{K}$ and $\mathrm{Na}$ in the effluent stream.

\section{Conclusion}

This study demonstrated that there exist alternative sustainable methods for cleaning wine tanks that reduce hazardous waste

Table 1: The cost, water use, and effluent measurements associated with cleaning a 100,000-litretank using the industry standard Sterox K as compared to the newly developed chemicals and water knife.

\begin{tabular}{|c|c|c|c|c|c|}
\hline 100,000 LitreTank & Sterox K & $\begin{array}{l}\text { Liquid } \\
\text { Ox NF }\end{array}$ & Clean & Vitipure & $\begin{array}{l}\text { W a } t \text { e } r \\
\text { Knife }\end{array}$ \\
\hline Cost of Cleaning (\$) & 25.12 & 23.92 & & 24.00 & 15.07 \\
\hline Water Usage (L) & 290 & 290 & & 290 & $1,247.29$ \\
\hline K (g/Tank) & 116.76 & 6.92 & & $\sim 0$ & - \\
\hline $\mathrm{Na}$ (g/Tank) & 542.61 & 23.83 & & $\sim 0$ & - \\
\hline
\end{tabular}

Table 2: A comparison of cost and effluent streams if all California wine was made in 600,000 litre tanks and cleaned with Sterox K as compared to Vitipure.

\begin{tabular}{|l|l|l|}
\hline & All Wine in CA \\
\hline & Sterox K & Vitipure \\
\hline Cost of Cleaning (\$) & $\$ 279,013$ & $\$ 261,879$ \\
\hline Necessary Water Usage (litre) & $5,346,842$ & $5,346,842$ \\
\hline K (ton) & 2.06 & $\sim 0$ \\
\hline Na (ton) & 9.60 & $\sim 0$ \\
\hline Electrical Conductivity (mS) & 24,911 & 5,954 \\
\hline Total Soluble Solids(g/L) & 6,177 & 9,721 \\
\hline COD (g/L) & 22,533 & $\sim 0$ \\
\hline
\end{tabular}


streams while cutting production costs. Taking a proactive stance on sustainability in the wine industry has allowed for research in this critical area to be conducted. These findings are especially important, given the current state of salinity and water in California. It also appears that without these efforts to reduce water usage and waste streams that regulatory bodies would eventually have to step in and potentially mandate solutions that are not as sustainable as those found here.

A comprehensive economic analysis of the impact of switching to green cleaning processes in the winery and food processing industry would require a complete lifecycle analysis folded into a state wide production model factoring in spillover effects of conversion. A lifecycle analysis compares the impact, both explicit and implicit, that alternative cleaning processes have from their production to their final use and disposal (sometimes referred to a cradle-to-grave analysis). This would include potential reductions in green house gas emissions (GHG), potential labour impacts, potential reductions in water use, and potential reductions in $\mathrm{K}$ and $\mathrm{Na}$ associated with the production, use, and disposal of the alternative cleaning processes. The state wide production model would estimate actual current wine tank use and cleaning practices and the conversion of those practices to green chemicals. However, we believe that the conservative estimates of state wide impacts given above are just that, conservative. There is a large potential for these new practices to have an effect on salinity in not only the San Joaquin Valley or California, but the entire global wine industry.

There is on-going analysis to see if a combination of the physical cleaning process mentioned above combined with the green chemicals tested in this analysis provides an even bigger impact on reducing effluent waste streams at a lower economic cost.

\section{References}

1. Howitt RE, Kaplan J, Larson D, MacEwan D, Medellín-Azuara J, et al. (2009) The economic impacts of Central Valley salinity. University of California Davis Final Report to the State Water Resources Control Board Contract. 05-417150-0.

2. Sunding $D L$ (1996) Measuring the marginal cost of nonuniform environmental regulations. Am J Agric Econ 78: 1098-1107.

3. Sunding D, RubinY, Berkman M (2006) Hilmar supplemental environmental project: Executive summary.

4. Cormier RJ, Mallet M, Chiasson S, Magnusson H, Valdimarsson G (2007) Effectiveness and performance of HACCP-based programs. Food Control 18 $665-671$

5. Simões M, Simões LC, Vieira MJ (2010) A review of current and emergent biofilm control strategies. LWT Food Sci Technol 43: 573-583.

6. Gibson H, Taylor JH, Hall KE, Holah JT (1999) Effectiveness of cleaning techniques used in the food industry in terms of the removal of bacterial biofilms. J Appl Microbiol 87: 41-48.
7. Mosse KP, Patti AF, Christen EW, Cavagnaro TR (2011) Review: Winery wastewater quality and treatment options in Australia. Aust J Grape Wine Res 17: 111-122.

8. Walker RR, Blackmore DH, Clingeleffer PR, Correll RL (2002) Rootstock effects on salt tolerance of irrigated field-grown grapevines (Vitis vinifera $\mathrm{L}$. cv. Sultana).: 1. Yield and vigour inter-relationships. Aust J Gape Wine Res 8: 3-14.

9. Tregeagle JM, Tisdall JM, Blackmore DH, Walker RR (2006) A diminished capacity for chloride exclusion by grapevine rootstocks following long-term saline irrigation in an inland versus a coastal region of Australia. Aust J Gape Wine Res 12: 178-191.

10. Singer MJ, Munns DN (2006) Soils: An introduction. Upper saddle river, NJ: Pearson Education inc.

11. Maas EV, Hoffman GJ (1977) Crop salt tolerance - Current assessment. J Irri Drainage Div ASCE 103: 115-134

12. Allison LE (1964) Salinity in relation to irrigation. In: Norman AG (Ed). Advances in agronomy 16: 139-180.

13. Rubin Y, Sunding D, Berkman M (2007) Hilmar supplemental environmental project: Executive summary. California Regional Water Quality Control Board.

14. Christ KL, Burritt RL (2013) Critical environmental concerns in wine production: an integrative review. J Clean Prod 53: 232-242.

15. Qadir M, Schubert S, Ghafoor A, Murtaza G (2001) Amelioration strategies for sodic soils: a review. Land Degrad Dev 12: 357-386.

16. Cimowski G, Cooley W, Grober L, Martin J, McCarthy M, et al. (2006) Salinity in the central valley: An overview. Regional Water Quality Control Board Central Valley Region.

17. Scott WG, Scott HM, Lake RJ, Baker MG (2000) Economic cost to New Zealand of foodborne infectious disease. N Z Med J 113: 281-284.

18. Brooks JD, Flint SH (2008) Biofilms in the food industry: problems and potential solutions. Int J Food Sci Technol 43: 2163-2176.

19. Scharff RL, McDowell J, Medeiros L (2009) Economic cost of foodborne illness in Ohio. J Food Prot 72: 128-136.

20. Jevons K, Awe M (2010) Economic benefits of membrane technology vs evaporator. Desalination 250: 961-963

21. Rasanen E, Nystrom M, Sahlstein J, Tossavainen O (2002) Purification and regeneration of diluted caustic and acidic washing solutions by membrane filtration. Desalination 149: 185-190.

22. Mosse KP, Verheyen TV, Cruickshank AJ, Patti Af, Cavagnaro TR (2013) Soluble organic components of winery wastewater and implications for reuse. Agric Water Manag 120: 5-10.

23. Vilar MJ, Rodriguez-Otero JL, Dieguez FJ, Sanjuan ML, Yus E (2008) Application of ATP bioluminescence for evaluation of surface cleanliness of milking equipment. Int J Food Microbiol 125: 357-361.

24. Verran J, Whitehead KA (2006) Assessment of organic materials and microbial components on hygenic surfaces. Food and Bioprod Process 84: 260-264.

25. Clark K (2001) How to develop and validate a total organic carbon method for cleaning applications. PDA J Pharm Sci Technol 55: 290-294.

26. Strege MA, Stinger TL, Farrell BT, Lagu AL (1996) Total organic carbon analysis of swab samples for the cleaning validation of bioprocess fermentation equipment. Biopharm Int.

\section{Acknowledgements}

This work was supported by the Wine Institute's California Department of Food \& Agriculture Specialty Crop Block Grant [SCB10024]. 